\title{
Prizes, Medals and Travelling Fellowships of The Royal College of Psychiatrists
}

\section{Gaskell Medal and Prize}

This Prize was instituted in 1886 and is named after Samuel Gaskell, Medical Superintendent of the County Asylum, Lancaster, after whom Gaskell House in Manchester is also named.

The Prize was established from a Trust Fund in memory of Dr Gaskell, but it is now supported almost entirely from College funds. It has increased in value over the years and now stands at $£ 500$ although the medal, originally gold, is now silver-gilt. Many of its holders have achieved distinction in psychiatry.

The Prize has always been considered one of the foremost academic distinctions in clinical psychiatry and members are asked to bring it to the notice of suitable candidates at their hospitals who may be eligible to compete.

Entry forms may be obtained on application to the Dean and should be completed and returned by 31 March 1990. An entry fee of $£ 30.00$ is charged, returnable to bona fide candidates. The annual examination for the Prize is held in May or June and includes a written paper, a clinical and an oral.

Full particulars of the Regulations are given below.

\section{Regulations}

The examinations will be held according to the terms of the Trust quoted below:

"Candidates must (a) have been qualified medical officers in one or more mental hospitals or clinics in psychiatry in the United Kingdom or elsewhere in the British Commonwealth for at least two years; (b) have passed the MRCPsych Examination within the last four years or possess any other degree or diploma in psychological medicine at an equivalent time."

\section{Research Prize and Bronze Medal}

The Bronze Medal was instituted in 1882 as an award for a dissertation on a clinical or pathological subject related to mental disorder, submitted to the Examiners by a medical officer below consultant status. It was usually published at a later date in the Journal of the RMPA and, latterly, the Royal College of Psychiatrists. In 1978 the Court of Electors agreed that there should be a new College Prize to replace the Bronze Medal and Prize and also the Divisional Prizes which had been available until that time.

The Prize is now worth $£ 500$ and the recipient receives a Bronze Medal. An opportunity may be given to recipients to report their reseach at a Quarterly Meeting of the College, subject to approval by the Programmes and Meetings Committee. The number of entrants for this Prize is usually small.
Nevertheless, the standard of topics is high and there have been a number of notable names among the winners.

The Prize may be awarded only to Members or Inceptors of the College below the rank of consultant psychiatrist or equivalent at the time the research is submitted to the Royal College. Research involving collaboration between workers, whether psychiatrists or in other disciplines, may be submitted, but the Prize may be shared between no more than two eligible psychiatrists. In each instance where collaborative research is submitted there should bea clearindication of which parts of the research were undertaken by each worker and a statement to this effect signed by all collaborating workers must be submitted.

The research should be presented in the form of an essay or dissertation with accompanying tables or figures and should not normally exceed 10,000 words (including tables, references and appendices). A collection of articles will not be accepted as a submission for the Research Prize, but work already published or submitted for a higher degree may be included in the submission if it is incorporated into the essay or dissertation.

The Examiners for the Research Prize will be nominated jointly by the Court of Electors and the Research Comnmittee. No Prize will be awarded if a sufficient standard is not reached.

Entries for the Prize should be submitted to the Dean by 31 March of each year. Reports received after this date will be accepted as entries for the Prize the following year.

\section{Laughlin Prize}

This Prize was awarded to the College in 1979 by $\mathrm{Dr}$ Henry P. Laughlin, founder and first President of the American College of Psychiatrists. Dr Laughlin was elected Corresponding Member of the RMPA in 1961 and Honorary Fellow of the College in 1976. He has always been a warm friend of British psychiatry and has attended a number of Annual Meetings.

The Prize is awarded to the candidate who obtains the highest marks and the best recommendation from the Examiners in the Membership Examination. The Prize is awarded twice a year after the Spring and Autumn Examinations and its value is currently $£ 250$.

\section{The Peter Scott Memorial Trust Scholarship}

The Scholarship is awarded biennially from funds subscribed in memory of the late Peter Scott, CBE. 
The Scholarship is intended to encourage young doctors or medical students to further their studies in the field of forensic psychiatry or delinquency by enabling them to carry out research, to travel, to write, to complete a research project or to suggest any other relevant activity. The value of the Scholarship is up to $£ 1,000$, and any member of the medical profession, or medical student(s), may apply. More than one Scholarship may be awarded. The successful candidate(s) will be required to supply a subsequent report and may be asked to present a paper at a meeting of the Royal College of Psychiatrists.

Application forms are obtainable from the Education Department, Royal College of Psychiatrists, 17 Belgrave Square, London SWIX 8PG, and should be completed and returned by 31 March 1990.

\section{Morris Markowe Public Education Prize}

This Prize was established in 1989 from funds donated in memory of the late Dr Morris Markowe, Honorary Fellow, and Registrar of the Royal College of Psychiatrists from 1972-78.

The Public Education Prize will be awarded annually for an article on a psychiatric topic of approximately 1000 words, suitable for publication in a regional newspaper, lay journal, the paramedical press or a general practitioner's magazine. At the time of submission, the article(s) submitted must not have been published previously.

Entries will be judged for topicality and newsworthiness by designated members of the College's Public Education Committee, and a Prize of $£ 200$ will be awarded for the successful entry.

The Prize may be awarded only to Members or Inceptors of the College below the rank of consultant psychiatrist or equivalent at the time the entry is submitted.

Entries for the Prize should be submitted to Professor B. Pitt, Public Education Officer, at the College, by 1 May of each year.

\section{Natalie Cobbing Travelling Fellowship (Psychiatry of Mental Handicap)}

The Fellowship derives from a bequest made by the late Miss Natalie Cobbing, Secretary of the RMPA and the Royal College of Psychiatrists for 25 years until her death in 1984. The Prize was first awarded in 1986.

A Fellowship (value $£ 2,000$ ) will be awarded every two years by the Royal College of Psychiatrists to further the training of specialists in this branch of psychiatry by enabling them to extend their experience with travel to appropriate centres overseas.

Applicants must submit an account of their previous experience in this field and a reasoned account of their training needs and how the subject might benefit from their use of the Fellowship. They must also submit evidence in the form of published or unpublished work that they would be an appropriate recipient of the Fellowship.

1. All applicants must possess the MRCPsych.

2. All applicants must be working in the United Kingdom or Republic of Ireland.

3. Applicants, who must be under the age of 40 , may be of Senior Registrar or Consultant status within three years of appointment.

4. Applicants must submit:

(i) a curriculum vitae;

(ii) the names of two referees;

(iii) a proposal as to how they might spend their time, with confirmation, if possible, from their host centre(s) abroad;

(iv) an account of original research, published or unpublished papers or reviews in the field of mental handicap or psychiatry.

In the case of joint research, the exact contribution of each author must be made clear.

5. Successful candidates will be expected to submit a short report to the College on their use of the Fellowship.

6. The awards will be made by a panel consisting of the Dean and two assessors nominated by the President and Chairman of the Mental Handicap Section respectively.

7. In the event of none of the applications being of a satisfactory standard, no award will be made.

8. Applications submitted after 31 March 1990 will be taken as applications for the following Fellowship.

\section{Lilly Travelling Fellowship}

This Fellowship, value $£ 7,750$, is open to members of the College working in the United Kingdom or the Republic of Ireland who are of Senior Registrar or Lecturer grade or equivalent, or are Consultants within three years of their first Consultant appointment.

The award is intended to cover expenses for travel abroad, to one or two centres, for a period of not less than three months, in pursuit of further study, research or clinical training relevant to the applicant's current interests. Applicants should include a curriculum vitae, a statement of current interests and planned study abroad, with supporting statements from the proposed host centre and the names of two referees; and confirmation from the applicant's employing authority that study leave would be granted if the applicant was successful.

Applications should be sent to the Dean of the College by 30 April 1990.

Professor A. C. P. Sims Dean 